\title{
Association between apoptosis inhibitor of macrophage and microsatellite instability status in colorectal cancer
}

\author{
Wen-juan Huang ${ }^{1 \dagger}$, Xin Wang ${ }^{1 \dagger}$, Meng-lin Zhang ${ }^{1}$, Li Li ${ }^{2 *}$ and Rui-tao Wang ${ }^{1 *}$ (D)
}

\begin{abstract}
Background: The microsatellite instability (MSI) in colorectal cancer (CRC) has a more favorable clinical outcome and is characterized by highly upregulated expression of various immunological checkpoints than microsatellite stable (MSS) tumors. Apoptosis inhibitor of macrophage (AIM) is a circulating protein and circulates throughout the body to remove cellular debris. The aim of this study was to evaluate the association between MSI status and AIM levels in CRC patients.
\end{abstract}

Methods: In this study, we evaluated the levels of AIM by Enzyme Linked Immuno-Sorbent Assay (ELISA) in serum of 430 CRC patients. All patients' clinical and laboratory characteristics at initial diagnosis were collected. The relationship between AIM levels and MSI status was examined.

Results: 64 patients (14.9\%) were identified as having MSI-H (high-frequency MSI) and 366 casess (85.1\%) having MSS. Patients with an MSI-H phenotype had lower AIM levels compared with MSS patients. Moreover, AIM levels were correlated with histological type and MSI status. Logistic regression analysis revealed that decreased AIM levels were independently associated with MSI-H phenotype after adjusting confounding factors.

Conclusion: Reduced AIM levels are associated with MSI-H subtyping of CRC. Further research on the involvement of AIM in MSI-H CRC is needed.

Keywords: Apoptosis inhibitor of macrophage, Microsatellite instability, Colorectal cancer

\section{Background}

Colorectal cancer $(\mathrm{CRC})$ was the third most common malignant cancer and the fourth leading cause of cancerrelated deaths worldwide [1]. Despite the advancement in comprehensive treatment, the long-term survival of CRC patients remains unsatisfactory. More than $20 \%$ of CRC patients were diagnosed with distant metastasis at

*Correspondence: 920221984@qq.com; ruitaowang@126.com

tWen-juan Huang and Xin Wang contributed equally to this work 1 Department of Internal Medicine, Harbin Medical University Cancer Hospital, Harbin Medical University, No. 150 Haping ST, Nangang District, Harbin, Heilongjiang 150081, China

${ }^{2}$ Department of Colorectal Surgery, Harbin Medical University Cancer Hospital, Harbin Medical University, No. 150 Haping ST, Nangang District, HarbinHeilongjiang 150081, China initial diagnosis [2]. The microsatellite instability (MSI) subtype of CRC accounts for approximately 15\% of colorectal cancers and results from the accumulation of frameshift mutations in target gene caused by a failure of the mismatch repair system [3]. MSI CRCs exhibit proximal colonic location, increased lymphocytic infiltration, and poorer response to chemotherapeutic drugs, and are characterized by highly upregulated expression of various immunological checkpoints $[4,5]$.

Apoptosis inhibitor of macrophage (AIM) is a circulating protein of approximately $40 \mathrm{kDa}$ and mainly produced by tissue-resident macrophages, including liver Kupffer cells and peritoneal macrophages [6]. AIM, a member of the scavenger receptor cysteine-rich 
superfamily, is discharged from a macrophage and circulates throughout the body to remove cellular debris [7]. Moreover, recent studies revealed that AIM plays key roles in lipid accumulation, acute kidney injury, acute myocardial infarction, acute lung injury, sepsis, hepatic fibrosis, and hepatocellular carcinoma [8-15].

However, there are few studies to evaluate AIM levels in patients with MSI CRCs. Therefore, the aim of this study was to compare MSI status with AIM levels in patients with CRC.

\section{Methods}

\section{Study population}

We studied 430 patients with CRC at the Harbin Medical University Cancer Hospital between January 2018 and December 2018. All patients were confirmed by histology. None of CRC patients received chemotherapy or radiotherapy. The exclusion criteria included hematological disorders, hypertension, and diabetes mellitus.

This study was approved by the Institutional Review Board of Harbin Medical University Cancer Hospital. All of the patients provided their written consent to participate in the study.

\section{Clinical examination and biochemical measurements}

Clinical and demographic characteristics of all patients were recorded, including smoking status, drinking status, medical history and medication use. A venous blood sample was collected in anticoagulant-free tube from each participant under fasting conditions prior to any treatment. The blood samples were centrifuged at $2500 \mathrm{~g}$ for $10 \mathrm{~min}$ and the serum was then stored at $-80{ }^{\circ} \mathrm{C}$. Routine blood tests were conducted in the hospital's clinical laboratory.

\section{ELISA measurements}

AIM was measured using a commercially available sandwich ELISA (CUSABIO, Wuhan, China) according to the recommendation of the manufacturer. Samples were measured as duplicates. The intra- and inter assay variation were below $8 \%$.

\section{MSI analysis}

DNA was obtained from fresh-frozen tumor tissue samples. MSI was assessed using polymerase chain reaction with primers amplifying the microsatellite markers, including BAT25, BAT26, NR-21, NR-24, and NR-27. MSI was graded as high (MSI-H) if at least three markers out of five were unstable, whereas MSS was defined as stable (MSS) if there were less than three unstable markers. There were no samples with only two unstable markers.

\section{Statistical analysis}

All data were presented as means \pm standard deviation or median (interquartile range) for continuous variables and percentages of the number for categorical variables. Normally distributed continuous variables in two groups were compared with the Student's $t$ test and skeweddistributed with the Mann-Whitney $U$ test. The chisquare test was used for categorical variables. Logistic regression analysis was carried out to evaluate clinicopathological factors that were associated with MSI-H status. The statistical analyses were performed using SPSS Statistics version 25.0 (SPSS Inc., Chicago, IL, USA). Receiver-operating characteristics (ROC) curve analysis was used to identify cut-off value of AIM using MedCalc version 15.0. A two-tailed $P<0.05$ indicated statistical significance.

\section{Results}

The study included 430 CRC patients between January 2018 and December 2018. Of the 430 participants entered, $245(57.0 \%)$ were men and 185 (43.0\%) were women. The mean ages were $59.5 \pm 9.9$ and $59.2 \pm 10.2$ years, respectively.

The characteristics of CRC patients are summarized according to MSI status in Table 1. There were no significant differences in gender, smoking status, drinking status, and creatinine levels between the two groups. CRC patients with MSI-H were young and had higher BMI, WBC, platelet count, AIM levels, and lower CEA and haemoglobin levels, compared to the patients with MSS.

The association between clinicopathological features and MSI status in CRC patients is shown in Table 2.

\begin{tabular}{|c|c|c|c|}
\hline Variables & MSI-H & MSS & P value \\
\hline Number & 64 & 366 & \\
\hline Age (years) & $59.4 \pm 11.8$ & $61.0 \pm 9.4$ & 0.328 \\
\hline Gender (female, \%) & $33(51.6)$ & $148(40.4)$ & 0.096 \\
\hline $\mathrm{BMI}\left(\mathrm{kg} / \mathrm{m}^{2}\right)$ & $24.5 \pm 3.3$ & $23.2 \pm 3.2$ & 0.004 \\
\hline Current smoker (\%) & $25(39.1)$ & $158(43.2)$ & 0.540 \\
\hline Drinker $(n, \%)$ & $17(26.6)$ & $122(33.3)$ & 0.285 \\
\hline Creatinine ( $\mu \mathrm{mol} / \mathrm{L})$ & $80.9 \pm 19.7$ & $81.1 \pm 18.4$ & 0.929 \\
\hline CEA $(\mathrm{ng} / \mathrm{mL})$ & $3.14(1.57-7.98)$ & $4.86(2.15-12.12)$ & 0.030 \\
\hline $\operatorname{WBC}\left(\times 10^{9} / \mathrm{L}\right)$ & $8.07 \pm 2.98$ & $6.92 \pm 2.30$ & 0.004 \\
\hline Haemoglobin (g/L) & $124.6 \pm 27.3$ & $134.3 \pm 22.4$ & 0.009 \\
\hline Platelet count $\left(\times 10^{9} / \mathrm{L}\right)$ & $309.6 \pm 121.8$ & $266.8 \pm 82.6$ & 0.008 \\
\hline AIM $(\mu \mathrm{g} / \mathrm{mL})$ & $5.89(1.37)$ & $6.86(1.49)$ & $<0.001$ \\
\hline
\end{tabular}

Data are presented as means (SD) or median (interquartile range) or percentage $B M I$ body mass index, CEA carcinoembryonic antigen, WBC white blood cells, AIM apoptosis inhibitor of macrophage 
Table 2 Correlations between clinicopathological features and MSI status in CRC

\begin{tabular}{|c|c|c|c|c|}
\hline Variables & $\begin{array}{l}\text { Total } \\
\text { n (\%) }\end{array}$ & $\begin{array}{l}\text { MSI-H } \\
\text { n (\%) }\end{array}$ & $\begin{array}{l}\text { MSS } \\
\text { n (\%) }\end{array}$ & $P$ value \\
\hline Tumor location & & & & $<0.001$ \\
\hline Proximal & $153(35.6)$ & $41(64.1)$ & $112(30.6)$ & \\
\hline Distal & $277(64.4)$ & $23(35.9)$ & $254(69.4)$ & \\
\hline Tumor size $(\mathrm{cm})$ & & & & 0.011 \\
\hline$<5.0$ & $282(65.6)$ & $33(51.6)$ & $249(68.0)$ & \\
\hline$\geq 5.0$ & $148(34.4)$ & $31(48.4)$ & $117(32.0)$ & \\
\hline Morphological type & & & & 0.717 \\
\hline Expansive & $155(36.0)$ & $21(32.8)$ & $134(36.6)$ & \\
\hline Infiltrative & $20(4.7)$ & $4(6.3)$ & $16(4.4)$ & \\
\hline Ulcerative & $255(59.3)$ & $39(60.9)$ & $216(59.0)$ & \\
\hline Histological type & & & & $<0.001$ \\
\hline Non-mucinous & $364(84.7)$ & $42(65.6)$ & $322(88.0)$ & \\
\hline Mucinous & $66(15.3)$ & $22(34.4)$ & $44(12.0)$ & \\
\hline Histological grade & & & & 0.008 \\
\hline $\begin{array}{l}\text { Well/moderately differenti- } \\
\text { ated }\end{array}$ & $308(71.6)$ & $37(57.8)$ & $271(74.0)$ & \\
\hline Poorly differentiated & $122(28.4)$ & $27(42.2)$ & $95(26.0)$ & \\
\hline Lymphatic invasion & & & & 0.030 \\
\hline Absent & $331(77.0)$ & $56(87.5)$ & $275(75.1)$ & \\
\hline Present & $99(23.0)$ & $8(12.5)$ & $91(24.9)$ & \\
\hline Tclassification & & & & 0.811 \\
\hline $\mathrm{T} 1+\mathrm{T} 2$ & $63(14.7)$ & $10(15.6)$ & $53(14.5)$ & \\
\hline $\mathrm{T} 3+\mathrm{T} 4$ & $367(85.3)$ & $54(84.4)$ & $313(85.5)$ & \\
\hline Lymph node metastasis & & & & 0.010 \\
\hline Absence & $267(62.1)$ & $49(76.6)$ & $218(59.6)$ & \\
\hline Presence & $163(37.9)$ & $15(23.4)$ & $148(40.4)$ & \\
\hline Distant metastasis & & & & 0.713 \\
\hline Absence & $382(88.8)$ & $56(87.5)$ & $326(89.1)$ & \\
\hline Presence & $48(11.2)$ & $8(12.5)$ & $40(10.9)$ & \\
\hline Stage & & & & 0.003 \\
\hline$|-| \mid$ & $258(60.0)$ & 49 (76.6) & $209(57.1)$ & \\
\hline III-IV & $172(40.0)$ & 15 (23.4) & $157(42.9)$ & \\
\hline
\end{tabular}

There were significantly positive correlations between MSI-H status and tumor location, tumor size, histological grade, lymphatic invasion, lymph node metastasis, clinical stage, and histological type. However, no correlations were found between MSI-H and T classification, and distant metastasis.

The median value of AIM was $6.8 \mu \mathrm{g} / \mathrm{mL}$ (range 3.6$12.3 \mu \mathrm{g} / \mathrm{mL}$ ). ROC analysis was used to assess the optimal cutoff value for AIM was 6.3 for MSI-H phenotype $(\mathrm{AUC}=0.715,95 \%$ CI 0.645-0.783, $\mathrm{p}<0.001$ ) (Fig. 1). CRC patients were divided into two groups according to the cutoff level. Of the total of 430 patients, 199 patients $(46.3 \%)$ were detected with AIM of less than or equal to $6.3 \mu \mathrm{g} / \mathrm{mL}$, while there were 231 patients

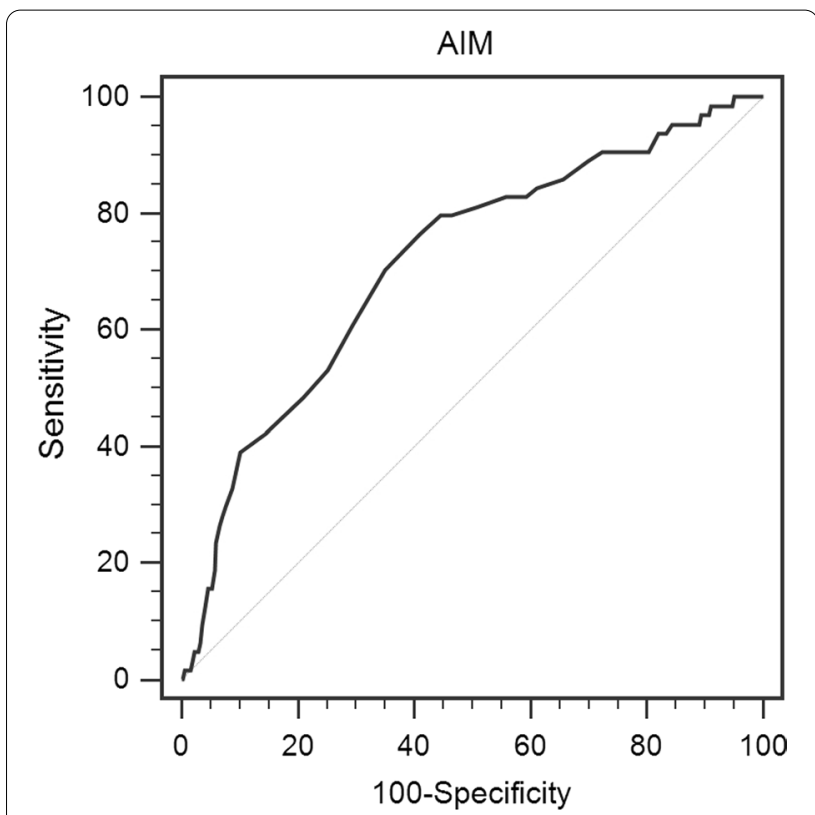

Fig. 1 Optimal cut-off value was determined for AIM using standard ROC curve analysis

(53.7\%) whose AIM levels were greater than $6.3 \mu \mathrm{g} /$ $\mathrm{mL}$. Correlations between AIM and clinicopathologic variables are presented in Table 3. There were significant differences in age, histological type, and MSI status. However, gender, BMI, smoking status, drinking status, WBC, haemoglobin, tumor size, tumor location, lymphatic invasion, venous invasion, $\mathrm{T}$ classification, lymph node metastasis, distant metastasis, and clinical stage in two groups did not show significant differences.

All CRC patients were classified into quartiles according to their AIM levels, including quartile 1 (Q1) $\leq 5.9 \mu \mathrm{g} / \mathrm{mL}, 5.9 \mu \mathrm{g} / \mathrm{mL}<$ quartile $2(\mathrm{Q} 2) \leq 6.5 \mu \mathrm{g} /$ $\mathrm{mL}, 6.5 \mu \mathrm{g} / \mathrm{mL}<$ quartile $3(\mathrm{Q} 3) \leq 7.2 \mu \mathrm{g} / \mathrm{mL}$, and quartile 4 (Q4) $\geq 7.3 \mu \mathrm{g} / \mathrm{mL}$ (Fig. 2). The percentages of patients with MSI-H in each group were $28.7 \%, 17.7 \%, 6.9 \%$ and $5.6 \%$, respectively. The results showed that as the serum AIM levels increased, the percentage of patients with MSI-H reduced.

Logistic regression analysis was performed to evaluate the clinicopathological factors that were associated with MSI-H status. Fourteen variables, including gender, BMI, WBC, haemoglobin, platelet count, CEA, AIM, tumor size, tumor location, lymphatic invasion, histological grade, histological type, lymph node metastasis, and clinical stage, were entered into the original equation. The factors found to be significantly associated with MSI-H in the regression analysis included BMI, WBC, platelet count, AIM, tumor size, tumor location, histological type, 
Table 3 Baseline characteristics of CRC patients according to AIM levels

\begin{tabular}{|c|c|c|c|c|}
\hline Variables & Total & $\mathrm{AIM} \leq 6.3$ & $A I M>6.3$ & $P$ \\
\hline Age (years) & & & & 0.002 \\
\hline$\leq 65$ & $282(65.6)$ & $115(57.8)$ & $167(72.3)$ & \\
\hline$>65$ & $148(34.4)$ & $84(42.2)$ & $64(27.7)$ & \\
\hline Gender & & & & 0.787 \\
\hline Male & $245(57.0)$ & $112(56.3)$ & $133(57.6)$ & \\
\hline Female & $185(43.0)$ & $87(43.7)$ & $98(42.4)$ & \\
\hline BMI $\left(\mathrm{kg} / \mathrm{m}^{2}\right)$ & $23.4 \pm 3.2$ & $23.6 \pm 3.4$ & $23.3 \pm 3.0$ & 0.333 \\
\hline Current smoker & & & & 0.359 \\
\hline Yes & $183(42.6)$ & $80(40.2)$ & $103(44.6)$ & \\
\hline No & $247(57.4)$ & $119(59.8)$ & $128(55.4)$ & \\
\hline Drinker & & & & 0.371 \\
\hline Yes & $139(32.3)$ & $60(30.2)$ & $79(34.2)$ & \\
\hline No & $291(67.7)$ & $139(69.8)$ & $152(65.8)$ & \\
\hline $\operatorname{WBC}\left(\times 10^{9} / \mathrm{L}\right)$ & $7.09 \pm 2.44$ & $7.11 \pm 2.61$ & $7.08 \pm 2.30$ & 0.923 \\
\hline Haemoglobin (g/L) & $132.9 \pm 23.4$ & $130.8 \pm 23.7$ & $134.7 \pm 23.1$ & 0.086 \\
\hline Platelet count $\left(\times 10^{9} / \mathrm{L}\right)$ & $273.1 \pm 90.6$ & $272.6 \pm 89.7$ & $273.6 \pm 91.6$ & 0.914 \\
\hline Creatinine $(\mu \mathrm{mol} / \mathrm{L})$ & $81.1 \pm 18.6$ & $82.6 \pm 22.3$ & $79.8 \pm 14.7$ & 0.132 \\
\hline CEA (ng/mL) & $4.37(2.03-11.31)$ & $3.82(1.94-13.70)$ & $4.67(2.12-10.67)$ & 0.768 \\
\hline Tumor size (cm) & & & & 0.738 \\
\hline$<5.0$ & $278(64.7)$ & $127(63.8)$ & $151(65.4)$ & \\
\hline$\geq 5.0$ & $152(35.3)$ & $72(36.2)$ & $80(34.6)$ & \\
\hline Tumor location & & & & 0.063 \\
\hline Proximal & $153(35.6)$ & $80(59.8)$ & $73(31.6)$ & \\
\hline Distal & $277(64.4)$ & $119(31.2)$ & $158(68.4)$ & \\
\hline Histological type & & & & 0.045 \\
\hline Non-mucinous & $364(84.7)$ & $161(80.9)$ & $203(87.9)$ & \\
\hline Mucinous & $66(15.3)$ & $38(19.1)$ & $28(12.1)$ & \\
\hline Histological grade & & & & 0.598 \\
\hline Well/moderately differentiated & $308(71.6)$ & $145(72.9)$ & $163(70.6)$ & \\
\hline Poorly differentiated & $122(28.4)$ & $54(27.1)$ & $68(29.4)$ & \\
\hline Lymphatic invasion & & & & 0.381 \\
\hline Absent & $331(77.0)$ & $157(78.9)$ & $174(75.3)$ & \\
\hline Present & $99(23.0)$ & $42(21.1)$ & $57(24.7)$ & \\
\hline T classification & & & & 0.061 \\
\hline $\mathrm{T} 1+\mathrm{T} 2$ & $63(14.7)$ & $36(18.1)$ & $27(11.7)$ & \\
\hline $\mathrm{T} 3+\mathrm{T} 4$ & $367(85.3)$ & $163(81.9)$ & $204(88.3)$ & \\
\hline Lymph node metastasis & & & & 0.377 \\
\hline Absence & $267(62.1)$ & $128(64.3)$ & $139(60.2)$ & \\
\hline Presence & $163(37.9)$ & $71(35.7)$ & $92(39.8)$ & \\
\hline Distant metastasis & & & & 0.709 \\
\hline Absence & $382(88.8)$ & $178(89.4)$ & $204(88.3)$ & \\
\hline Presence & $48(11.2)$ & 21 (10.6) & $27(11.7)$ & \\
\hline Stage & & & & 0.134 \\
\hline$|-| \mid$ & $258(60.0)$ & $127(63.8)$ & $131(56.7)$ & \\
\hline III-IV & $172(40.0)$ & $72(36.2)$ & $100(43.3)$ & \\
\hline MSI status & & & & $<0.001$ \\
\hline MSS & $366(85.1)$ & $150(75.4)$ & $216(93.5)$ & \\
\hline MSI-H & 64 (14.9) & $49(24.6)$ & $15(6.5)$ & \\
\hline
\end{tabular}




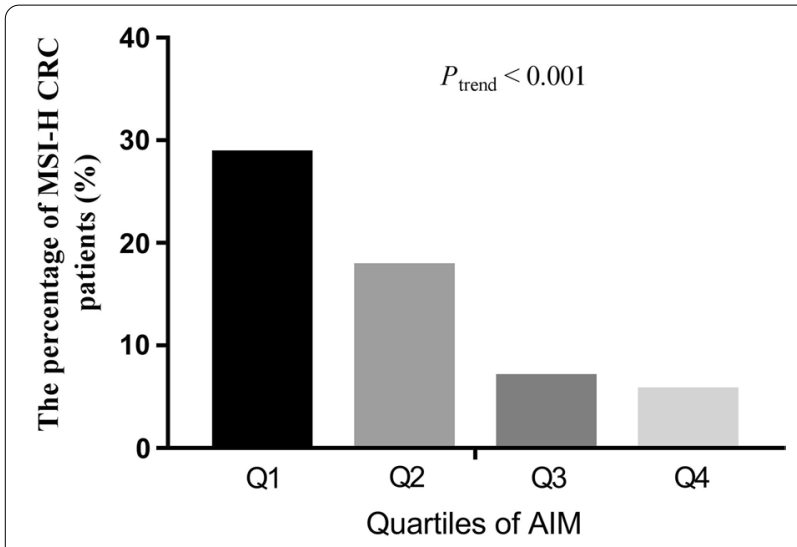

Fig. 2 The association between the percentages of MSI-H CRC and AIM levels

Table 4 Logistic regression analysis to evaluate the associations between MSI status and clinical factors

\begin{tabular}{|c|c|c|c|}
\hline Variables & $\beta$ & OR $(95 \% \mathrm{Cl})$ & $P$ value \\
\hline Gender (female vs male) & 0.520 & $1.682(0.842-3.360)$ & 0.141 \\
\hline $\mathrm{BMI}\left(\mathrm{kg} / \mathrm{m}^{2}\right)$ & 0.158 & $1.171(1.054-1.301)$ & 0.003 \\
\hline WBC $\left(\times 10^{9} / L\right)$ & 0.142 & $1.152(1.014-1.310)$ & 0.030 \\
\hline Haemoglobin (g/L) & 0.000 & $1.000(0.985-1.014)$ & 0.957 \\
\hline Platelet count $\left(\times 10^{9} / \mathrm{L}\right)$ & 0.005 & $1.005(1.001-1.009)$ & 0.021 \\
\hline CEA (ng/ml) & -0.004 & $0.996(0.985-1.008)$ & 0.549 \\
\hline $\operatorname{AIM}(\mu \mathrm{g} / \mathrm{mL})$ & -0.646 & $0.524(0.375-0.731)$ & $<0.001$ \\
\hline \multicolumn{4}{|l|}{ Tumor size $(\mathrm{cm})$} \\
\hline$(\geq 5.0$ vs $<5.0)$ & 1.178 & $3.249(1.631-6.474)$ & 0.001 \\
\hline \multicolumn{4}{|l|}{ Tumor location } \\
\hline (Proximal vs distal) & 1.203 & $3.330(1.642-6.752)$ & 0.001 \\
\hline \multicolumn{4}{|l|}{ Histological type } \\
\hline (Mucinous vs non-mucinous) & 1.452 & $4.273(1.974-9.248)$ & $<0.001$ \\
\hline \multicolumn{4}{|l|}{ Histological grade } \\
\hline $\begin{array}{c}\text { (Poorly differentiated vs well/ } \\
\text { moderately differentiated) }\end{array}$ & 1.361 & $3.900(1.881-8.086)$ & $<0.001$ \\
\hline \multicolumn{4}{|l|}{ Lymphatic invasion } \\
\hline (Presence vs absence) & -0.695 & $0.499(0.186-1.339)$ & 0.168 \\
\hline \multicolumn{4}{|l|}{ Lymph node metastasis } \\
\hline (Presence vs absence) & 0.629 & $1.875(0.188-18.671)$ & 0.592 \\
\hline \multicolumn{4}{|l|}{ Stage } \\
\hline$(I I I+|\mathrm{V} v s|+\mid I)$ & -1.863 & $0.155(0.015-1.600)$ & 0.118 \\
\hline
\end{tabular}

Data are presented as means (SD) or median (interquartile range) or percentage $B M I$ body mass index, WBC white blood cells, AIM apoptosis inhibitor of macrophage

and histological grade (Table 4). Notably, reduced AIM levels were associated with a higher risk of MSI-H phenotype after adjusting for other confounding variables.

\section{Discussion}

It has been shown for the first time that AIM levels were significantly reduced in MSI-H CRC patients compared with those in MSS CRC patients. AIM levels were correlated with age, histological type, and MSI status. Moreover, AIM levels were independently associated with MSI-H phenotype.

Macrophages in tumor microenvironment play a vital role in tumor development, angiogenesis, and metastasis $[16,17]$. Recent studies confirmed that macrophages modulates the immune response against pathogens and maintains tissue homeostasis in cancer [18]. The main chemokines secreted from cancer cells attract macrophage and promote the expansion and dissemination of cancer cells [19]. Many reports demonstrated that tumor associated macrophages (TAMs) are one of the key targets to improve the efficacy of immunotherapies as these cells can suppress the functions of $\mathrm{CD}^{+} \mathrm{T}$ and NK cells [20]. M2-like TAMs are thought to drive neoangiogenesis, suppress the adaptive immune response, and promote tumor cell proliferation, invasion, and metastasis [18]. High TAM density was associated with worse survival in oral cancer, breast cancer, gastric cancer, bladder cancer, and ovarian cancer [20]. However, high TAM density has a better survival in CRC patients with or without metastases [21-23].

The exact mechanisms of AIM in MSI-H CRCs were currently unclear. AIM was recognized to have an apoptosis inhibitory function for macrophages, $\mathrm{T}$ cells, and natural killer T cells [24]. However, AIM had different effects in different cancers. AIM overexpression in myeloid cells led to the formation of lung adenocarcinoma in a transgenic mouse model [25]. However, AIM-deficient mice were highly susceptible to steatosis-associated the development of hepatocellular carcinoma [26]. The difference of AIM in different CRC subtypes supports the crucial roles that macrophages play on immune cells. AIM acts as a marker for phagocytes so that they can efficiently recognize and engulf the debris as their target [7]. Moreover, the phagocytic activities performed by the non-professional phagocytes contribute to the physiological tissue turnover or remodeling, leading to maintenance of the tissue homeostasis. AIM plays a crucial role in obesity-induced inflammation in white adipose tissue as characterized by decreased proinflammatory M1 macrophages but increased anti-inflammatory M2 macrophages [6]. A recent report revealed that glycogen synthase kinase 3 modulates obesity-induced visceral adipose tissue inflammation by inhibiting AIM production in macrophages [27].

Consistent to our results, previous studies showed that the CD8 T effector gene signature was significantly upregulated in MSI-H tumors compared with MSI-L/ 
MSS tumors [28]. Moreover, a report demonstrated that $\mathrm{CD} 8(+)$ cytotoxic $\mathrm{T}$ lymphocytes may lead to increased platelet destruction in immune thrombocytopenia [29].

In this study, we found that activated platelets are involved in different CRC subtypes. Therefore, investigating the mechanism of AIM involved in MSI-H CRCs may be helpful for guiding treatment strategy in different CRC subtypes.

Some limitations of the present study need to be acknowledged: First, the study was performed in a single hospital. Second, our data can not provide a mechanistic explanation for our findings. Third, the results cannot be generalized because the study included only Chinese patients.

\section{Conclusions}

AIM levels were decreased in MSI-H CRCs. Further mechanistic research was needed.

\section{Abbreviations}

AIM: Apoptosis inhibitor of macrophage; CRC: Colorectal cancer; MSI: Microsatellite instability; MSS: Microsatellite stable.

\section{Acknowledgements \\ Not applicable.}

\section{Authors' contributions}

RTW conceived the study; WJH, XW, LL, and RTW participated in the design; $\mathrm{LL}, \mathrm{XW}, \mathrm{WJH}$, and MLZ collected the data; WJH, LL and XW performed statistical analyses and drafted the manuscript. LL, MLZ, and RTW edited and checked the manuscript. All of the authors have read and approved the final manuscript.

\section{Funding}

This study was jointly supported by the Haiyan Foundation of Harbin Medical University Cancer Hospital (JJZD2017-05), and the Nn10 Program of Harbin Medical University Cancer Hospital (20160003). The funding body was not involved in study design, data collection, analysis, data interpretation, or in writing the manuscript.

\section{Availability of data and materials}

The data in this study available from the corresponding author on reasonable request.

\section{Ethics approval and consent to participate}

The protocol was approved by the ethical committee review board of Harbin Medical University Cancer Hospital. All patients involved in the study gave written consent for this study.

\section{Consent to publish}

Not applicable.

\section{Competing interests}

The authors declare that they have no competing interests.

Received: 1 August 2020 Accepted: 2 November 2020 Published online: 10 November 2020

\section{References}

1. Jemal A, Siegel R, Xu J, Ward E. Cancer statistics, 2010. CA Cancer J Clin. 2010;60(5):277-300.
2. Mattiuzzi C, Sanchis-Gomar F, Lippi G. Concise update on colorectal cancer epidemiology. Ann Transl Med. 2019;7(21):609.

3. Gelsomino F, Barbolini M, Spallanzani A, Pugliese G, Cascinu S. The evolving role of microsatellite instability in colorectal cancer: a review. Cancer Treat Rev. 2016:51:19-26.

4. Evrard C, Tachon G, Randrian V, Karayan-Tapon L, Tougeron D. Microsatellite instability: diagnosis, heterogeneity, discordance, and clinical impact in colorectal cancer. Cancers (Basel). 2019;11(10):1567.

5. Cohen R, Rousseau B, Vidal J, Colle R, Diaz LA, André T. Immune checkpoint inhibition in colorectal cancer: microsatellite instability and beyond. Target Oncol. 2020;15(1):11-24.

6. Arai S, Miyazaki T. Impacts of the apoptosis inhibitor of macrophage (AIM) on obesity-associated inflammatory diseases. Semin Immunopathol. 2014:36(1):3-12

7. Arai S, Miyazaki T. A scavenging system against internal pathogens promoted by the circulating protein apoptosis inhibitor of macrophage (AIM). Semin Immunopathol. 2018;40(6):567-75.

8. Iwamura Y, Mori M, Nakashima K, et al. Apoptosis inhibitor of macrophage (AIM) diminishes lipid droplet-coating proteins leading to lipolysis in adipocytes. Biochem Biophys Res Commun. 2012:422(3):476-81.

9. Mera K, Uto H, Mawatari S, et al. Serum levels of apoptosis inhibitor of macrophage are associated with hepatic fibrosis in patients with chronic hepatitis C. BMC Gastroenterol. 2014;14:27.

10. Arai S, Kitada K, Yamazaki T, et al. Apoptosis inhibitor of macrophage protein enhances intraluminal debris clearance and ameliorates acute kidney injury in mice. Nat Med. 2016;22(2):183-93.

11. Nishikido T, Oyama J, Shiraki A, Komoda H, Node K. Deletion of apoptosis inhibitor of macrophage (AIM)/CD5L attenuates the inflammatory response and infarct size in acute myocardial infarction. J Am Heart Assoc. 2016;5(4):e002863.

12. Ozawa T, Maehara N, Kai T, Arai S, Miyazaki T. Dietary fructose-induced hepatocellular carcinoma development manifested in mice lacking apoptosis inhibitor of macrophage (AIM). Genes Cells. 2016;21(12):1320-32.

13. Koyama N, Yamazaki T, Kanetsuki Y, et al. Activation of apoptosis inhibitor of macrophage is a sensitive diagnostic marker for NASH-associated hepatocellular carcinoma. J Gastroenterol. 2018:53(6):770-9.

14. Kimura H, Suzuki M, Konno S, et al. Orchestrating role of apoptosis inhibitor of macrophage in the resolution of acute lung injury. J Immunol. 2017;199(11):3870-82.

15. Gao X, Liu Y, Xu F, et al. Assessment of apoptosis inhibitor of macrophage/ CD5L as a biomarker to predict mortality in the critically ill with sepsis. Chest. 2019;156(4):696-705

16. Dehne N, Mora J, Namgaladze D, Weigert A, Brüne B. Cancer cell and macrophage cross-talk in the tumor microenvironment. Curr Opin Pharmacol. 2017;35:12-9.

17. Mills CD, Lenz LL, Harris RA. A breakthrough: macrophage-directed cancer immunotherapy. Cancer Res. 2016:76(3):513-6.

18. Mehla K, Singh PK. Metabolic regulation of macrophage polarization in cancer. Trends Cancer. 2019:5(12):822-34.

19. Unver N. Macrophage chemoattractants secreted by cancer cells: sculptors of the tumor microenvironment and another crucial piece of the cancer secretome as a therapeutic target. Cytokine Growth Factor Rev. 2019:50:13-8.

20. Cassetta L, Kitamura T. Macrophage targeting: opening new possibilities for cancer immunotherapy. Immunology. 2018;155(3):285-93.

21. Forssell J, Oberg A, Henriksson ML, Stenling R, Jung A, Palmqvist R. High macrophage infiltration along the tumor front correlates with improved survival in colon cancer. Clin Cancer Res. 2007;13(5):1472-9.

22. Cavnar MJ, Turcotte S, Katz SC, et al. Tumor-associated macrophage infiltration in colorectal cancer liver metastases is associated with better outcome. Ann Surg Oncol. 2017;24(7):1835-42.

23. Zhou Q, Peng RQ, Wu XJ, et al. The density of macrophages in the invasive front is inversely correlated to liver metastasis in colon cancer. J Transl Med. 2010;8:13.

24. Kurokawa J, Nagano H, Ohara O, et al. Apoptosis inhibitor of macrophage (AIM) is required for obesity-associated recruitment of inflammatory macrophages into adipose tissue. Proc Natl Acad Sci U S A. 2011:108(29):12072-7.

25. Li Y, Qu P, Wu L, Li B, Du H, Yan C. Api6/AIM/Spa/CD5L overexpression in alveolar type II epithelial cells induces spontaneous lung adenocarcinoma. Cancer Res. 2011;71(16):5488-99. 
26. Maehara N, Arai S, Mori M, et al. Circulating AIM prevents hepatocellular carcinoma through complement activation. Cell Rep. 2014;9(1):61-74.

27. Wang $L$, Wang $Y$, Zhang $C$, et al. Inhibiting glycogen synthase kinase 3 reverses obesity-induced white adipose tissue inflammation by regulating apoptosis inhibitor of macrophage/CD5L-mediated macrophage migration. Arterioscler Thromb Vasc Biol. 2018;38(9):2103-16.

28. Kikuchi T, Mimura K, Okayama H, et al. A subset of patients with MSS/ MSI-low-colorectal cancer showed increased CD8(+) TILs together with up-regulated IFN-ץ. Oncol Lett. 2019;18(6):5977-85.
29. Qiu J, Liu X, Li X, et al. CD8(+) T cells induce platelet clearance in the liver via platelet desialylation in immune thrombocytopenia. Sci Rep. $2016 ; 6: 27445$

\section{Publisher's Note}

Springer Nature remains neutral with regard to jurisdictional claims in published maps and institutional affiliations.
Ready to submit your research? Choose BMC and benefit from:

- fast, convenient online submission

- thorough peer review by experienced researchers in your field

- rapid publication on acceptance

- support for research data, including large and complex data types

- gold Open Access which fosters wider collaboration and increased citations

- maximum visibility for your research: over $100 \mathrm{M}$ website views per year

At BMC, research is always in progress.

Learn more biomedcentral.com/submissions 